\title{
Cerebellar Hemorrhage Revealing a Community Acquired Bacterial Meningitis: A Rare Complication
}

\author{
Rida Touab, MD*, Mohammed Rabii Andaloussi, MD, Khalil Mounir, PhD, Mustapha \\ Bensghir, PhD and Hicham Belkhi, PhD
}

Department of Anesthesiology and Critical Care, Military Training Hospital Mohammed V, Rabat, Morocco

*Corresponding author: Rida Touab, MD, Department of Anesthesiology and Critical Care, Military Training Hospital Mohammed V, Ahmed Reda Gudira Street, Nahda1, Rabat, Morocco

\begin{abstract}
Background: Hemorrhagic stroke can be an exceptional complication of meningitis and constitute a differential diagnosis in our observation.

Case report: A 73-year-old man, with a history of arterial hypertension, chronic smoking for 25 years, and has been abstinent for 30 years.

The patient had had a fever of $38{ }^{\circ} \mathrm{C}$ for one week before admission with vomiting, headache complicated by altered consciousness, with suspension of contact.

The patient had a Glascow Coma Scale at 10, and normal hemodynamic and respiratory parameters. CT scan was objective a cerebellar hematoma in the vermis without a compression signs. Lambar punction had objective a shady cerebrospinl fluid, with 234 white elements and Streptococcus $B$ in the gram coloration.

Treatment had included third generation cephalosporin with control of arterial pressure. Evolution was favorable whiting 48 hours.
\end{abstract}

Conclusion: In this case we report a hemorrhagic complication of bacterial meningitis with a favorable evolution.

\section{Keywords}

Hemorrhage, Stroke, Meningitis, Complications

\section{Key Message}

Think about looking for meningitis in front of an atypical intracerebral hemorrhage.

\section{Introduction}

\section{Background}

The morbidity and mortality of community-acquired bacterial meningitis continue to be substantial in spite of advances in medical care: Diagnosis and therapeutic [1].

Hemorrhagic stroke can be an exceptional complication of meningitis and constitute a differential diagnosis in our observation.

We report a case of cerebellar hematoma complicating purulent meningitis: An unusual location.

\section{Case report}

A 73-year-old man, with a history of arterial hypertension treated with a calcium channel blocker, chronic smoking for 25 years, and has been abstinent for 30 years.

The patient had had a fever of $38^{\circ} \mathrm{C}$ for one week before admission with vomiting, headache complicated by altered consciousness, with suspension of contact and inadequate response to stimulation.

The patient presented to the emergency department with a physical examination that showed a Glascow Coma Scale at 10/15: Eyes opening at 2, motor response at 5 , and verbal response rated at 3 , no focal deficit, without pupils abnormalities, with bilateral nystagmus and dysarthria. He was hemodynamically stable with systolic blood pressure at $145 \mathrm{mmHg}$, diastolic blood pressure at $80 \mathrm{mmHg}$ and heart rate at 109 beats per minute. He was eupneic with a pulse oxygen saturation of $94 \%$, capillary blood glucose of $1.2 \mathrm{~g} / \mathrm{l}$, and temperature of $37.6{ }^{\circ} \mathrm{C}$. On admission to the emergency room, the patient was placed in supine position with head ele- 
vated at $30^{\circ}$, monitored, with peripheral venous access, gastric and urinary catheterization.

A morphological assessment including a cerebral tomodensitometry was carried out and revealed a hematoma at the level of the vermis of $3 \mathrm{~cm} / 2 \mathrm{~cm}$, without signs of compression of the fourth ventricle or the brain stem, without other abnormalities at the supra-tentorial stage.

A bacteriological evaluation including a lumber puncture had objective a shady cerebrospinl fluid, with 234 white elements in direct examination, predominantly by neutrophilic polynuclear elements, with a culture recovered 48 hours after isolation of a Streptococcus B. Biochemical analysis had found a hyper-proteinorachy at $1.52 \mathrm{~g} / \mathrm{l}$ and a glycorachy at $0.2 \mathrm{~g} / \mathrm{l}$ compared to a concomitant capillary glycemia at $1.56 \mathrm{~g} / \mathrm{l}$.

An inflammatory syndrome was positive with C-reactive protein at $150 \mathrm{mg} / \mathrm{l}$ and procalcitonin at $1.08 \mathrm{ng} / \mathrm{l}$.

The haemoglobin level was $12 \mathrm{~g} / \mathrm{dl}$, hyperleukocytosis at $13000 / \mathrm{mm}^{3}$ with PNN predominance.

Kidney function and blood ionogram with liver workup were normal.

The search for pulmonary, ORL, dental or infectious endocarditis was negative.

The patient was admitted to the intensive care unit for management, which is based on blood pressure control by continuous intravenous infusion of nicardipine at $4 \mathrm{mg} /$ hour, with a target systolic blood pressure of less than $140 \mathrm{mmHg}$, avoiding hypotension, with control of systemic secondary brain injury, by setting up an oxygen therapy by nasal cannula at a flow rate of one liter per minute ensuring a $96 \% \mathrm{SpO}_{2}$, a $\mathrm{PaCO}_{2}$ on arterial blood was at $37 \mathrm{mmHg}$, and the glycemia was maintained at a value between 1.4 and $1.8 \mathrm{~g} / \mathrm{l}$, with treatement of fever by paracetamol at a dose of $15 \mathrm{mg} / \mathrm{Kg}$, i.e $1000 \mathrm{mg}$ repeated after six hours if needed. A cerebral angioscan was performed showing no abnormalities.

Antibiotic therapy with ceftriaxone at a dose of 100 $\mathrm{mg} / \mathrm{Kg}$, i.e $7000 \mathrm{mg}$ divided into two daily doses, was started as soon as the results of the direct examination, preceded by corticotherapy with dexamethasone at a dose of $0.15 \mathrm{mg} / \mathrm{Kg}$, i.e $10.5 \mathrm{mg} / 6 \mathrm{H}$, and maintained for four days.

The remander of the treatment included a basic ration, $10 \%$ glucose serum bolus if needed, prevention of thromboembolic disease by support stocking, prevention of stress ulcer by a proton pump inhibitor, with protection of support points and introduction of enteral feeding via the gastric tube.

The evolution after 48 hours was favourable: Apyrexia obtained improvement of consciousness disorders with a GCS at 14/15, with appearance of cerebellar syndrome and a decrease in the biological inflammatory syndrome.

\section{Discussion}

The vascular complications of community-acquired bacterial meningitis are known to be rare, particularly those hemorrhagic [2]. They significantly increase morbidity (96\%) and mortality (67\%) [3]. Intracranial hemorrhage can be either intra-parenchymal or subarachnoid. In a review of the literature [2] the authors noted three articles describing intracranial hemorrhage complicating bacterial meningitis: Gironell, et al. [4] reporting three patients with a supra-tentorial location, a Danish cohort studied by Bodilsen, et al. [5] reporting three patients with one cerebellar location similar to our patient, but in hemispheric cerebella. The third review did not specify the location of hematoma.

The incidence of this complication is about 3\% [3-5], but it reaches $19.9 \%$ when all cerebrovascular complications are taken into account $[3,5]$.

Risk factors have been reported such as anticoagulation and Staphylococcus aureus infection [3].

The diagnosis is made by imaging, generally a brain CT scan but sometimes the detection of micro-bleeding requires magnetic resonance imaging.

Imaging is required when clinical manifestations such as headache aggravation, alteration of consciousness, signs of focusing. In our patient, the imaging was performed first in front of the alteration of consciousness, which was indicative of an intra-cerebellar hematoma, but in front of the clinical-radiological discordance a lumber puncture was performed which was indicative a bacterial meningitis representing probably the cause of hematoma, since the patient's blood pressure was controlled, the location of hematoma was atypical compared to hemorrhagic stroke causing by hypertensive emergency, and the exploration of cerebral circulation was normal.

The pathophysiology of these hemorrhage remains poorly identified based on theories including vessel destruction via subarachnoid inflammation [2] or rupture of microaneurysms developed in response to inflammation [3]. In other pathway, dysregulation of both the coagulation and fibrinolytic pathways, not only systemically but also locally in the central nervous system compartment [6-8], local depletion of coagulation factors, which together with microvascular damage, vasculitis and cerebral infarction, might lead to the observed manifest cerebral hemorrhages [9]. Cerebral blood flow with impaired autoregulation may also lead to local hyperperfusion and possibly result in cerebral haemorrhage [4].

\section{Conclusion}

In this case we report a hemorrhagic complication of bacterial meningitis with a favorable evolution. 


\section{References}

1. Swartz MN (2004) Bacterial meningitis-a view of the past 90 years. N Engl J Med 351: 1826-1828.

2. Swartz MN (1984) Bacterial meningitis. More involved than just the meninges. N Engl J Med 311: 912-914.

3. Mook-Kanamori BB, Fritz D, Brouwer MC, van der Ende A, van de Beek D (2012) Intracerebral hemorrhages in adults with community associated bacterial meningitis in adults: Should we reconsider anticoagulant therapy? PLoS One 7: e45271.

4. Gironel A, Domingo P, Mancebo J, Coll P, Marti-Vilalta JL (1995) Hemorrhagic stroke as a complication of bacterial meningitis in adults: Report of three cases and review. Clin Infect Dis 21: 1488-1491.

5. Bodilsen J, Dalager-Pedersen M, Schonheyder HC, Nielsen $\mathrm{H}$ (2014) Stroke in community-acquired bacterial meningitis: A Danish population-based study. Int $\mathrm{J}$ Infect Dis 20: 18-22.
6. Kowalik MM, Smiatacz T, Hlebowicz M, Pajuro R, Trocha H (2007) Coagulation, coma, and outcome in bacterial meningitis-an observational study of 38 adult cases. J Infect 55: 141-148.

7. Weisfelt M, Determann RM, de Gans J, van der Ende A, Levi M (2007) Procoagulant and fibrinolytic activity in cerebrospinal fluid from adults with bacterial meningitis. J Infect 54: $545-550$

8. Winkler F, Kastenbauer S, Koedel U, Pfister HW (2002) Role of the urokinase plasminogen activator system in patients with bacterial meningitis. Neurology 59: 1350-1355.

9. Vergouwen MD, Schut ES, Troost D, van de Beek D (2010) Diffuse cerebral intravascular coagulation and cerebral infarction in pneumococcal meningitis. Neurocrit Care 13: 217-227. 